\section{Mercury poisoning in Ontario}

Are Canada's Indians now victims of Minamata disease? David Spurgeon reports from Ottawa

IN THE spring of 1970 , the minister of energy and resources management of the province of Ontario announced that the fish in the English-Wabigoon river system contained high levels of methylmercury and were unfit for human consumption. The sequence of events since then has seen the disruption of the way of life of hundreds of Indians in the area, the closure of a prosperous recreational fishing lodge there, serious doubt cast on the capacity of governments to deal with such issues, and a human tragedy recalling the mercury poisonings at Minamata, Japan.

Dr Masazumi Harada of Kumamoto University in Japan, a neuropsychiatrist and expert on Minamata disease, noted neurological symptoms in many Indians he examined in the area."There were 37 cases in which some type of sensory disturbance was found," he reported. "Impairment of the visual field was found in 16 cases. Seven of these cases had asymmetric constriction and tunnel vision. This is very significant in Minamata disease." (Harada's italics). He was a member of a Japanese delegation that included victims of Minamata disease which last September visited the Canadian settlements affected at White Dog and Grassy Narrows Reserves, near Kenora, in northern Ontario.

The energy and resources minister singled out a paper company's chemical manufacturing plant as the cause of the mercury contamination in the area. Over the previous eight years it was said to have dumped eight tons of methyl mercury into the river system seventy miles upstream.

The process in which the mercury was used has now been replaced, but the advice given by the Ontario government to anglers is to fish for fun only. All commercial fishing licences held by the Indians were revoked in 1970 by the government, which has since supplied them fish to eat from other lakes. This removed a major source of income for the Indians, but it did not stop them eating contaminated fish. And in Grassy Narrows Reserve, where there had never been much reliance on government welfare support, welfare payments are now the principal source of income.

On the government's role, the Canadian Broadcasting Corporation has referred in its programmes to reports that were ignored or never came to light. Newspapers point to a conflict of jurisdiction between federal and provincial governments.

The line taken by government medical men is revealed by Dr James Stopps, senior consultant on environmental health for the Ontario government, who says "to date no Indian has been diagnosed as having mercury poisoning. That doesn't mean no cases exist; it does mean that after five years we haven't been able to find one." $\mathrm{Dr}$ Harada, however, says "even a conservative estimate is that the effect of methylmercury among seven cases cannot be denied." Critics further maintain that the Government's tests were carried out during the mid-winter rather than at the height of the fisheating season; that it did not test some of the people who ate the most fish (the guides); and that it noted only the mercury levels of the individuals, not their symptoms.

The latest chapter in the story is found in an interim report, published by the federal health department, on a survey of residents of the White Dog and Grassy Narrows Reserves. The purpose of the survey was to determine the extent of exposure to mercury and whether such exposure is causing adverse effects on health; the report which deals with samples of hair and blood obtained at the reserves last August, was written by Dr T. W. Clarkson, professor and director of the Centre in Environmental Health Sciences of the University of Rochester's medical school and a consultant to the Research Institute of the Hospital for Sick Children in Toronto.

"The results obtained to date (December 1975) indicate a wide range of mercury levels-from less than 5 parts per $10^{\circ}$ to 330 parts per $10^{\circ}$ in blood," the report said. "The exposure to mercury usually follows a yearly cycle with the highest intake in the summer. Adult males acting as guides at fishing camps have the highest intake of mercury. Five guides out of eleven that were sampled had blood levels in the range of 100 to 330 parts per $10^{9}$. Analysis of hair samples from the guide having the highest blood concentration (330 parts per $\left.10^{9}\right)$ revealed that the peak mercury concentration had occurred two months prior to the collection of the blood sample. This peak value in hair was close to 150 parts per million, equivalent to a blood concentration of approximately 500 parts per $10^{9} "$.

The report also revealed that wives

\section{Sorry, for copyright reasons some images on this page may not be available online}

of guides tended to have higher blood levels of mercury than other females on the reserve. Children usually had lower levels than their parents, but younger children tended to have higher levels than older ones. "A matter of serious concern is the continued exposure of pregnant women to methylmercury," it said. By contrast, analyses of blood samples received from women (mostly non-Indians) living in or around nearby Kenora, and received from the Lake of the Woods Hospital, Kenora, revealed no significant exposure to methylmercury at the time of the delivery of their babies.

A thorough clinical evaluation of the health of those sampled will not appear until phase two of the study. But the report "tentatively" concluded that "several individuals in both reserves still have unacceptably high blood levels of methylmercury . . . very high exposure to methylmercury continues to be a serious problem with guides working at fishing camps." It noted that the highest concentrations reported occurred in the summer of 1975 "despite the fact that warnings against eating contaminated fish have been in effect for several years and that an intensive health education campaign has been in effect during the past year."

The report recommended further action by the guides' employers and health authorities to reduce exposure, and high priority for the planned expansion of a clinical programme. It recommended continuation of the health education programme andbecause "the mercury problem may continue for some time"--establishment of a National Centre in Environmental Health. Such a centre, the report said, could deal with other environmental pollutants as well as methylmercury, and "would help detect and deal with potential threats long before they emerged as a national problem." 